\title{
CURSO DE ESPECIALIZAÇÃO EM ENFERMAGEM - MODALIDADE RESIDÊNCIA: EXPERIÊNCIA DE IMPLANTAÇÃO EM UM HOSPITAL-ESCOLA
}

\begin{abstract}
Alba Lucia Botura Leite de Barros*
Jeanne Liliane Marlene Michel**

BARROS, A.L.B.L.de; MICHEL, J.L.M. Curso de especialização em enfermagem - modalidade residência: experiência de implantação em um hospital-escola. Rev.latino-am.enfermagem, Ribeirão Preto, v. 8, n. 1, p. 5-11, janeiro 2000 .

Relatamos aqui a implantação de um Curso de Especialização em Enfermagem na modalidade "Residência", no hospitalescola da Universidade Federal de São Paulo, cuja estrutura respeita as exigências legais para os cursos de pós-graduação "lato sensu", porém com características semelhantes às da Residência Médica, no que diz respeito ao desenvolvimento das atividades práticas. Tem por objetivos: 1) Capacitar enfermeiras, em diversas áreas de especialidade, através de intenso programa de treinamento em serviço, em regime de tempo integral e dedicação exclusiva; 2) Contribuir com a implementação do cuidado sistematizado de enfermagem; e 3) Melhorar a qualidade da assistência de enfermagem prestada no Hospital São Paulo. Os resultados levam-nos a crer que este seja um caminho para preparar enfermeiras para prestar uma assistência de qualidade, além de contribuir para o desenvolvimento de trabalhos cientificos voltados para a prática profissional.
\end{abstract}

UNITERMOS: especialização, enfermagem, enfermagem-residência

\section{INTRODUÇÃO}

Em fevereiro de 1979, o então Departamento de Enfermagem da Escola Paulista de Medicina iniciou a primeira turma de alunas do Curso de Especialização em Enfermagem Médico-Cirúrgica. O seu objetivo principal era qualificar docentes, do próprio Departamento e de outras escolas do país, atendendo a recomendação do Ministério da Educação, uma vez que a pós-graduação "stricto sensu" na Enfermagem era ainda incipiente no país, e havia urgência em preparar professores para as novas escolas que se abriam ${ }^{12}$. Nos anos 80 , este objetivo gradualmente foi sendo atingido, além de aumentarem as possibilidades de cursos de Mestrado e Doutorado para enfermeiros. Com isso, verificamos que a clientela que procurava o referido Curso estava mudando de perfil: o número de docentes decrescia e aumentava a procura por parte de enfermeiros do campo.

Paralelamente a isto, a coordenação do curso começou a discutir o seu conteúdo, dentro do contexto da polêmica existente então, sobre a formação generalista "versus" especialista. Em 1990, o Departamento de
Enfermagem passou a oferecê-lo, experimentalmente, em dois módulos: um, contendo assuntos de interesse geral da profissão e o outro, com assuntos específicos relacionados às áreas de especialidades médicas, em que era verificada maior demanda por parte das enfermeiras, além de serem voltadas às doenças prevalentes em nosso meio. Assim, o aluno poderia optar por uma área de concentração, o que caracterizaria realmente a sua condição de especialista ${ }^{12}$.

Apesar das mudanças, as avaliações demonstraram que persistia a preocupação dos docentes em relação à qualidade do especialista que estava sendo formado, desta vez devido às características da própria clientela: 1- muitas enfermeiras que procuravam o curso eram liberadas por suas instituições para estudar, como premiação pelo tempo de serviço. Ocorria, porém, que estas enfermeiras não iriam aplicar os conhecimentos adquiridos, pois na maioria das vezes ocupavam cargos administrativos; 2- por tratar-se de curso em período integral as enfermeiras, freqüentemente, não conseguiam dispensa de seus serviços, necessitando trabalhar à noite para se manterem. Em virtude disso, seu rendimento

\footnotetext{
* Professor Livre Docente da Disciplina Fundamentos de Enfermagem e Enfermagem Médico-Cirúrgica do Departamento de Enfermagem da Universidade Federal de São Paulo. Doutora em Ciências. Diretora de Enfermagem do Hospital São Paulo. Criadora do Curso de Especialização em Enfermagem - Modalidade Residência

** Professor Auxiliar da Disciplina Fundamentos de Enfermagem e Enfermagem Médico-Cirúrgica do Departamento de Enfermagem da Universidade Federal de São Paulo. Coordenadora Técnico-Administrativa da Diretoria de Enfermagem do Hospital São Paulo. Assistente de Coordenação do Curso de Especialização em Enfermagem - Modalidade Residência
} 
enquanto alunas ficava muito comprometido, pois estavam sempre muito cansadas devido à dupla jornada.

Diante destes problemas, em 1991 a Coordenação optou por interromper o curso, para uma completa reavaliação do mesmo.

Por outro lado, em 1992, houve um convite, por parte do então Diretor Superintendente do Hospital São Paulo, para que a Diretoria de Enfermagem passasse a ser ocupada por uma docente do Departamento de Enfermagem, com o objetivo de reaproximá-lo da direção do referido hospital, num processo de reintegração docente assistencial. Este era também um anseio de enfermeiras, funcionários do hospital e de alguns docentes, que, através de uma comissão, solicitavam a participação dos docentes de enfermagem na direção da assistência.

Ao assumirmos a Diretoria de Enfermagem do Hospital São Paulo, observamos que, além da reestruturação administrativa que se fazia necessária, era preciso melhorar a qualidade da assistência oferecida aos pacientes. As enfermeiras do Hospital vinham trabalhando sem um rumo definido, assumindo freqüentemente um papel meramente burocrático e de "bombeiro", resolvendo questões práticas, resultantes da ineficiência de outros serviços (lavanderia, almoxarifado, manutenção, etc), que dificultavam o provimento da assistência de enfermagem aos pacientes. Não havia registro sistematizado dos cuidados que eram prestados, e as enfermeiras manifestavam descontentamento generalizado com o seu trabalho.

Utilizando o referencial de DONABEDIAN ${ }^{10}$, verificamos que seria preciso modificar primeiramente a estrutura existente, para depois adequarmos o processo de enfermagem e posteriormente avaliarmos os resultados obtidos com as mudanças implementadas.

Dentre os inúmeros problemas estruturais encontrados, destacavam-se três situações: a elevada rotatividade entre as enfermeiras, o número insuficiente e a falta de preparo das mesmas, em sua maioria recémformadas. Procuramos então, através do Serviço de Educação Continuada (cuja coordenação também foi assumida por uma docente), recompor gradualmente $o$ quadro de enfermeiras do hospital, além de montar um programa de treinamento para as recém-admitidas. Empenhamo-nos também junto à Diretoria do Hospital, no sentido de melhorar os salários, de forma a facilitar a captação de recursos humanos. Observávamos, entretanto, que, mesmo com estas providências, a característica de hospital terciário (com alguns serviços de nível quaternário) da instituição exigia profissionais mais preparadas: embora quantitativamente houvesse uma recomposição do quadro, qualitativamente persistiam algumas deficiências, pois mesmo com o treinamento inicial, as enfermeiras recém-formadas demonstravam dificuldade para desempenhar o seu papel. Além disso, ocorria que, ao término de alguns meses, após finalmente adquirirem destreza e segurança, estas enfermeiras recebiam propostas de trabalho de outras instituições, que ofereciam salários mais altos, e acabavam pedindo demissão.

Tornava-se necessário encontrar uma fórmula que nos permitisse, preservando a vocação de hospital de ensino, continuar servindo de veículo para o treinamento e aperfeiçoamento profissional de jovens enfermeiras, porém fixando-as por um tempo maior (pelo menos dois anos) na instituição, para que pudesse usufruir dos investimentos nesse treinamento. Também era preciso encontrar mecanismos que estimulassem as enfermeiras a ampliar seus conhecimentos, e valorizar a sua atuação através dos registros escritos. Daí surgiu a idéia de criar um Curso de Especialização - Modalidade Residência, semelhante à Residência Médica ${ }^{9}$, porém com características próprias do trabalho na Enfermagem, cuja estrutura respeitasse as exigências legais para os cursos de pós-graduação "lato sensu" ". Esta idéia foi acolhida com entusiasmo pelo então Diretor Superintendente do Hospital São Paulo, que se dispôs a financiar bolsas, no mesmo valor das oferecidas aos médicos residentes pelo MEC, além de garantir às enfermeiras residentes igual tratamento aos demais residentes, em todos os aspectos (garantir moradia, alimentação, assistência médica, etc). Estas enfermeiras estagiariam nas unidades do hospital, na condição de residentes, não fazendo parte do quadro de funcionários, prestando assistência aos pacientes, sob orientação de docentes do Departamento de Enfermagem.

Em fevereiro de 1995 iniciamos o programa, utilizando o arcabouço do Curso de Especialização em Enfermagem Médico-Cirúrgica pré-existente ${ }^{4}$, com os seguintes objetivos:

I. Capacitar enfermeiros, em diversas áreas de especialidade, através de intenso programa de treinamento em serviço, em regime de tempo integral e dedicação exclusiva;

II. Contribuir na implementação do cuidado sistematizado de enfermagem no Hospital São Paulo, através da atuação das residentes nas unidades em que estagiam, executando o processo de enfermagem proposto pela Diretoria de Enfermagem;

III. Melhorar a qualidade da assistência de enfermagem prestada no Hospital São Paulo, através do aumento do número de enfermeiras atuando nas enfermarias, além da capacitação das enfermeiras do quadro efetivo do Hospital, pelo contato com as residentes, professores e preceptores que as orientam.

Relatamos a seguir, um breve histórico sobre a situação da residência em enfermagem no Brasil, a maneira como foi estruturado este programa, além dos resultados obtidos desde a sua criação em 1995 até 1997. 
2. A RESIDÊNCIA EM ENFERMAGEM NO BRASIL

A instituição da modalidade de formação "Residência em Enfermagem", no Brasil, tem suscitado discussões desde a década de 70, quando, em decorrência do Plano Nacional de Pós-Graduação, do MEC, foi criado o Programa de Pós-Graduação em Enfermagem e foram realizados estudos para avaliar a situação da profissão no Brasil e análise dos cursos oferecidos na época, por especialistas nacionais e estrangeiros ${ }^{12}$. Passou-se a estimular a criação de cursos de pós-graduação "lato sensu", como rápida solução para a qualificação docente, mas sem destacar a especialização de enfermeiras dos serviços de saúde.

A questão da capacitação técnica das enfermeiras de campo, entretanto, continuava sendo uma preocupação. Neste sentido, a residência apresentava-se como uma modalidade de especialização que atenderia sobretudo às condições dos grandes centros, onde a assistência à saúde se apresenta em maior nível de sofisticação, tornando necessária maior especialização. LIMA \& PORTO $^{11}$, face a estas considerações, apontam a residência como uma alternativa de atendimento à necessidade sentida pelas enfermeiras e pela comunidade. Relatam, ainda, que a Residência em Enfermagem implantou-se no Brasil em 1961, no Hospital Infantil do Morumbi, em São Paulo, e que, desde então, algumas experiências vinham sendo desenvolvidas.

Em 1978, a Associação Brasileira de Enfermagem (ABEn) realizou um seminário sobre a Residência, no Rio de Janeiro, cujas "recomendações", publicadas em $1979^{1}$, alertam para a inexistência de consenso sobre o assunto e propõem normas para a implementação dessa modalidade. Esse documento demonstra uma preocupação em caracterizar a residência como modalidade de curso de especialização, em que há ênfase no ensino eminentemente prático, sem excluir o aprofundamento de conhecimentos teóricos e o desenvolvimento de pesquisa em enfermagem.

Ao longo dos anos 80, algumas experiências continuaram sendo feitas no país, porém sem que houvesse consenso e regulamentação específica da matéria. No início da década de 90, o Conselho Federal de Enfermagem (COFEn) e a ABEn retomaram estudos sobre o assunto, visando configurar uma proposta de regulamentação.

Em agosto de 1994, a Comissão Permanente de Educação da ABEn - Nacional realizou, em Salvador, uma Oficina de Trabalho intitulada "Residência em Enfermagem no Brasill", dando seqüência à deliberação do I Seminário Nacional de Educação em Enfermagem, ocorrido em maio do mesmo ano, no Rio de Janeiro. Nessa oficina, houve relatos de experiência, a análise e caracterização da residência, além do estabelecimento de algumas diretrizes e encaminhamentos. No documento final ${ }^{2}$, haviam divergências entre as experiências apresentadas quanto à duração e carga horária, além das áreas a serem oferecidas. Expressa também a tendência de criticar tal tipo de curso em virtude de, por exemplo: "priorizar questões da tecnologia e do trabalho e secundarizar as necessidades de saúde da população"; ser um modelo que "não é capaz de atender às demandas da sociedade e nem realizar um trabalho que cause impacto no perfil epidemiológico da população"; por ser uma "alternativa para suprir as deficiências da graduação"; e por ter sido "criado para suprir déficit de pessoal dos serviços de saúde".

Esta postura extremamente cética por parte do grupo de trabalho (da Oficina), entretanto, não impediu que o COFEn prosseguisse com as discussões sobre o tema e, em setembro do mesmo ano, ao final do Seminário Nacional do Sistema COFEn/COREN's realizado em Salvador, emitisse documento sobre a residência, compilando as últimas propostas de alteração de um anteprojeto de lei, a ser encaminhado ao Congresso para apreciação ${ }^{5}$. Deste documento, resultou a versão final do Anteprojeto de Lei ${ }^{6}$, que dispõe sobre a Residência em Enfermagem, criando a Comissão Nacional de Residência de Enfermagem e outras providências. Esse anteprojeto desenhava um Curso de "pós-graduação "lato sensu" destinado a enfermeiras, sob a forma de especialização, sob a responsabilidade de uma Universidade, Instituição de Ensino Superior de Enfermagem ou Instituto de Pesquisa, público ou privado, caracterizado pelo aprofundamento do conhecimento científico e proficiência técnica decorrentes de treinamento em serviço, em regime de tempo integral". Tratava-se de uma proposta bastante consistente em seu conteúdo, que propunha um programa com a duração mínima de 02 anos, correspondendo a 3.800 horas.

Em 1996, o Deputado Paulo Rocha (PT-PA), contatado pela assessoria parlamentar do COFEn, apresentou o Projeto Lei n. ${ }^{\circ} 2.264 / 1996^{3}$, cuja redação final apresenta de forma sucinta a proposta do anteprojeto inicial, da Residência em Enfermagem, normatizando a sua instituição.

Esse Projeto de Lei foi submetido ao Conselho Nacional de Saúde (CNS) em 06/03/97, e o parecer apresentado pela conselheira Lucimar Cannon ${ }^{8}$ foi favorável, fazendo apenas duas ressalvas: no artigo $4^{\circ}$, estabelecendo que a Residência em Enfermagem, tal como a Residência Médica, deverá ter duração mínima de 1 ano, correspondendo a uma carga horária de 1.900 horas e no artigo $8^{\circ}$, acrescentando que o benefício de alojamento, providenciado pelas Instituições para os residentes, deverá ser usufruído apenas por aqueles que não residem no município onde se realiza o curso. 
Tendo este parecer do C.N.S. sido emitido, a assessora parlamentar do COFEn, Doranilde Barbosa, através do Informe Parlamentar n. ${ }^{\circ} 005 / 97^{7}$, relata que existe também um outro Projeto de Lei, n. ${ }^{\circ}$ 2.322/96, de autoria do deputado José Priante (PMDB-PA), tramitando conjuntamente na Comissão de Trabalho da Câmara dos Deputados e que trata do mesmo assunto. Tal assessoria sugere ao COFEn uma audiência com o Deputado Sérgio Arouca, relator desta Comissão, para tratar do seu parecer.

Assim, observamos que existe todo um movimento dos órgãos dirigentes da Enfermagem no Brasil, no sentido de instituir efetivamente esta modalidade de pós-graduação, que vem sendo experimentada há algum tempo.

\section{O PROGRAMA DE RESIDENCIA EM ENFERMAGEM DO DEPARTAMENTO DE ENFERMAGEM DA UNIFESP}

\subsection{Estrutura do curso}

O nosso Programa foi criado a partir da mescla entre a estrutura de um Curso de Especialização ${ }^{4}$ e o modelo da Residência Médica ${ }^{9}$, sendo denominado "Curso de Especialização em Enfermagem - Modalidade Residência". Propositalmente, foi deixado o termo "em Enfermagem", sendo a área especificada somente no certificado de conclusão, de forma a permitir ao curso abranger todas as áreas da Enfermagem.

O curso tem duração de 02 (dois) anos, com carga horária semanal de 60 horas, num total de 5.600 horas (2.800 por ano). Destas, 630 horas (cerca de 12\%) constituem carga horária teórica. Todas as horas restantes são para atividades práticas e teórico-práticas.

Enquanto pós-graduação "lato sensu", apresenta conteúdo teórico de curso de especialização, que inclui as disciplinas: Metodologia de Pesquisa, Didática, Bioestatística e Introdução à Informática, além da obrigatoriedade de apresentação, pela aluna, de uma monografia. Considerando a característica eminentemente prática desejada ao curso, foram também instituídas algumas disciplinas que julgávamos importantes para o desenvolvimento das habilidades das enfermeiras residentes, tais como: Fundamentos teóricos de ciências básicas aplicadas à Enfermagem (que aprofunda conceitos nas áreas de Anatomia, Fisiologia, Patologia e Farmacologia), Diagnóstico por imagem aplicado à Enfermagem, Epidemiologia Clínica, Enfermagem em Saúde Pública e Sistematização da Assistência de Enfermagem, além de conteúdos teóricos específicos da área escolhida pela aluna.

O conteúdo prático é desenvolvido sob a forma de intenso treinamento em serviço, tendo sido planejado nos moldes da Residência Médica: durante o primeiro ano, a enfermeira faz estágios de 1 mês, rodiziando por diversas unidades do hospital, de forma a ter uma noção geral de funcionamento do mesmo, além de ter oportunidade de utilizar os conceitos de Propedêutica e Diagnóstico por Imagem que está aprendendo e de aplicar a assistência sistematizada, junto a pacientes de várias especialidades, diversificando assim a sua experiência. No segundo ano, cada enfermeira vai para a área previamente escolhida, aprofundando-se na especialidade.

Durante todo o curso, cada residente deve cumprir um plantão semanal de 12 horas nos finais de semana e feriados, que poderá ser diurno ou noturno, conforme escala a ser determinada pela coordenadora da área em que o mesmo está estagiando.

O Curso iniciou-se em 1995 com 18 vagas, tendo passado a 20 vagas em 1996 e 27 em 1997. Estas são distribuídas entre 10 especialidades: Pneumologia, Cardiologia, Nefrologia, Epidemiologia Hospitalar, Neurocirurgia, UTI, Ortopedia, Centro Cirúrgico, Emergência e Clínica Médica (incluindo Geriatria). Cada uma destas áreas é coordenada por uma docente (doutora, mestre ou mestranda, atendendo às exigências de titulação necessárias para cursos de especialização) do Departamento de Enfermagem que, juntamente com enfermeiras destacadas para este fim, supervisionam as atividades dos residentes, discutem casos clínicos, orientam a sua atuação, avaliam o seu desempenho e planejam o desenvolvimento dos estágios e conteúdo teórico.

As professoras, juntamente com a Coordenadora do Curso (que atualmente é também a docente que ocupa a Diretoria de Enfermagem do Hospital São Paulo) e com representantes das residentes do $1^{\circ}$ e $2^{\circ}$ ano $\left(R_{1}\right.$ e $\left.R_{2}\right)$, compõem a Comissão de Residência em Enfermagem (COREEN), colegiado criado para debater e decidir os rumos do Programa na UNIFESP. Este colegiado, referendado pelo Conselho do Departamento de Enfermagem, está vinculado ao Conselho de Extensão, que é coordenado pelo Pró-Reitor de Extensão da Universidade.

O subsídio financeiro para as bolsas pagas aos residentes é, no momento, totalmente proporcionado pela Superintendência do Hospital São Paulo, assim como a alimentação dos mesmos no refeitório do hospital. O alojamento oferecido às enfermeiras provenientes de outros municípios é mantido pela Universidade, bem como, o benefício de assistência médica, proporcionado pelo Serviço de Saúde dos Alunos. Desde o início do programa, ficou acordado que as enfermeiras residentes teriam exatamente os mesmos benefícios ${ }^{9}$ que os médicos residentes (inclusive no tocante ao valor da bolsa), como 
uma forma de garantir o seu "status quo" na Instituição. A Coordenação do Curso, com o aval do COFEn e juntamente com o Pró-Reitor de Extensão da Universidade, iniciou gestões junto ao MEC, no sentido de obter o reconhecimento do programa, para que o Ministério venha a assumir o custeio das bolsas, como ocorre com a Residência Médica, de forma a diminuir o ônus financeiro do Hospital. Além disso, a bolsa oficial propiciaria às residentes garantias trabalhistas, que permitem o cômputo do período de residência como tempo de serviço, para fins de aposentadoria. Enquanto não obtêm estas vantagens, as alunas têm sido orientadas a obterem registro como trabalhadores autônomos e a recolherem a previdência social, para garantirem a aposentadoria no futuro.

Para subsidiar o trabalho da Coordenação do Curso, foi elaborado um Regulamento, baseado nos dispositivos da Residência Médica e dos Cursos de Especialização já existentes, que contém a estrutura do Curso, além dos direitos e deveres das enfermeiras residentes. Após sua aprovação pela Comissão de Residência em Enfermagem, foi levado aos Conselhos do Departamento de Enfermagem e de Extensão da UNIFESP, para referendamento.

\subsection{Características da clientela}

A clientela do Programa de Residência é composta por enfermeiras recém-graduadas. Com relação à sua procedência, observamos que vem havendo uma mudança de perfil nos últimos três anos: a turma de 1995 iniciou-se com 18 alunas, havendo posteriormente três desistências. Das 15 enfermeiras que efetivamente permaneceram no Programa, 13 (86\%) eram provenientes de São Paulo (Capital) e, na sua maioria, ex-alunas da própria instituição. Apenas 2 alunas (14\%) vinham de outros estados (Rio de Janeiro e Bahia).

Em 1996, abriram-se 20 vagas e houve apenas uma desistência, ficando a turma com 19 alunas, sendo que destas, 12 (63\%) eram provenientes de São Paulo (Capital) e cerca de metade das mesmas procedentes de outras escolas da cidade, além da UNIFESP. As demais vinham: 3 (16\%) do interior do estado, 2 (11\%) de Minas Gerais, $1(5 \%)$ da Bahia e 1 (5\%) do Maranhão.

O grupo de $R_{1}$, de 1997, é composto de 27 enfermeiras e nele observamos uma inversão do quadro: menos da metade da turma $(48 \%, n=13)$ é da Capital, e as restantes provêm do interior do estado de São Paulo $(37 \%, \mathrm{n}=10)$ e de outros estados, sendo 2 de Minas Gerais (7\%), 1 da Bahia (4\%) e uma do Paraná (4\%).

Verificamos, portanto, uma tendência a ampliar a abrangência na população, fazendo com que o curso prepare profissionais que venham a disseminar os seus conhecimentos por todo o país. Por outro lado, a própria heterogeneidade dos grupos que ingressam anualmente faz com que se torne necessário um programa intensivo de conteúdo teórico e treinamento, que permita às alunas compensarem desigualdades em sua formação e obterem um rendimento adequado.

\section{3 Áreas Oferecidas}

A escolha inicial das áreas que seriam oferecidas baseou-se na experiência anterior com o Curso de Especialização em Enfermagem Médico-Cirúrgica, além de dados epidemiológicos de prevalência e da nossa vivência diária de docentes na Diretoria de um grande hospital.

Em 1995, as nossas 15 alunas foram assim distribuídas: Pronto Socorro (3), UTI (3), Cardiologia (2), Pneumologia (2), Nefrologia (2), Centro Cirúrgico (1) e Ortopedia (1).

A experiência com esta primeira turma permitiu uma avaliação em relação à demanda, e observamos que as áreas de maior procura eram UTI, Cardiologia, Pronto Socorro e Nefrologia. Inicialmente, havia uma proposta de oferecer 2 vagas por área, porém, dada a variação de demanda, decidimos ampliar o número de vagas por área conforme a procura.

No ano de 1996, acrescentaram-se as áreas de Clínica Médica (que inclui a Geriatria) e Epidemiologia Clínica (que inclui o Controle de Infecções, Controle de Qualidade e Vigilância Epidemiológica) e foram criadas 2 novas vagas, ficando as alunas com a seguinte distribuição: Pronto Socorro (2), UTI (3), Cardiologia (1), Pneumologia (2), Clínica Médica (2), Nefrologia (3), Epidemiologia Clínica (2), Centro Cirúrgico (2) e Ortopedia (2).

Em virtude dos bons resultados observados, para o ano de 1997 solicitamos ao Diretor Superintendente do Hospital São Paulo a ampliação do número de vagas, e foram autorizadas mais 7 vagas, chegando-se a um total de 27. Decidiu-se abrir a área de Neurocirurgia e manter um número maior de residentes nas áreas de maior procura, ficando assim a distribuição: Pronto Socorro (3), UTI (4), Cardiologia (4), Pneumologia (3), Clínica Médica (2), Nefrologia (2), Epidemiologia (2), Centro Cirúrgico (3), Ortopedia (2) e Neurocirurgia (2).

\section{AVALIAÇÃO DOS RESULTADOS}

Apesar de tratar-se de um programa recente, os resultados obtidos até o momento têm sido muito satisfatórios.

A primeira turma, que concluiu o curso em janeiro de 1997, formou 15 profissionais diferenciadas, 
que imediatamente se inseriram no mercado de trabalho em boas colocações. Algumas delas optaram por ficar na própria Instituição, contratadas como enfermeiras e inscreveram-se nos programas de mestrado. Uma das exalunas foi convidada a compor o quadro de enfermeiras preceptoras da Residência, auxiliando a professora responsável pela área de Emergências, e tem contribuído na coordenação da assistência prestada na sala de emergência do Pronto-Socorro.

Observamos que a criação da Residência em Enfermagem tornou-se um marco em termos de qualidade da assistência de enfermagem prestada no hospital: além da óbvia relação numérica, proporcionada pela presença das residentes como um contigente extra nas unidades onde estagiam, verificamos que, em virtude do preparo diferenciado, elas contribuem efetivamente para a mudança de comportamento das colegas em relação ao trabalho ali desenvolvido. Inicialmente, houve alguns problemas de relacionamento, causados sobretudo pela insegurança das enfermeiras das unidades em relação ao papel que as residentes iriam desempenhar, além das inevitáveis comparações entre o valor da bolsa dos residentes e o salário das enfermeiras. Gradualmente, entretanto, foi-se delineando melhor este papel e, sob a supervisão muito próxima das docentes e enfermeiras preceptoras, as tensões foram diminuindo a presença das residentes passou a funcionar como um estímulo para as demais enfermeiras, que se interessavam em participar das atividades, como estudos de caso e discussões clínicas. Muitas enfermeiras começaram a procurar cursos de pós-graduação e a se interessar pelo projeto de sistematização da assistência, que começamos a desenvolver em conjunto com a Residência. Também a presença de docentes constantemente nas unidades, participando do planejamento da assistência durante todo o ano (e não apenas durante os estágios dos alunos de graduação, como ocorria anteriormente), fortaleceu o vínculo do Departamento de Enfermagem com o Hospital, e contribuiu efetivamente para a melhora da qualidade da assistência. É interessante observar a repercussão disso em todo o hospital, que pode ser medida pela atitude da equipe médica: docentes médicos questionam freqüentemente a não existência de residentes de enfermagem em suas unidades, ou indagam: "quando vão chegar as "nossas" residentes ?".

Por outro lado, observamos também que a presença das residentes contribui de forma efetiva no ensino das alunas de graduação, e que por serem também "alunas", as residentes esforçam-se em ajudá-las, além de participar do ensino da Semiologia, com excelentes resultados. As alunas sentem-se à vontade junto das enfermeiras residentes e estas oferecem um modelo profissional importante. Desta forma, a docente pode contar com a residente atuando como uma espécie de "monitora", facilitando o processo ensino-aprendizagem, sobretudo quando o grupo tem mais de 6 ou 7 alunas.

Por fim, a exposição das monografias ao final do curso, mostrou trabalhos de excelente qualidade, que foram desenvolvidos nas unidades do hospital e postos em prática, trazendo assim contribuição efetiva e duradoura para as mesmas.

\section{CONCLUSÃO E PERSPECTIVAS}

Criado há três anos, o Programa de Residência em Enfermagem ainda está em fase de implantação, embora os primeiros resultados sejam animadores. Apesar de críticas em relação à extensa carga horária, concluímos que a mesma é necessária para manter o nível de treinamento que objetivamos para as nossas residentes. Verificamos que através desta estratégia é possível preparar enfermeiras provenientes das mais diferentes formações, e transformá-las em profissionais altamente capacitadas.

Observamos também que a Residência repercutiu favoravelmente na assistência de enfermagem prestada no hospital e no ensino de graduação. Em termos institucionais, evidenciou-se uma mudança de atitude da comunidade em relação às enfermeiras, que vêm obtendo maior credibilidade e respeito por seu desempenho profissional, além do fortalecimento da relação entre profissionais, as docentes de enfermagem e as do campo.

Assim, acreditamos estar atingindo os objetivos propostos e pretendemos empenhar-nos para dar seguimento ao projeto, ampliando o número de vagas e de áreas oferecidas. Estamos trabalhando para a aprovação do projeto do Curso pelo MEC, para obtermos o financiamento de bolsas, que nos permitirá ampliar o programa. Pretendemos também trabalhar pela regulamentação da Residência em Enfermagem junto ao COFEn, para garantir o padrão de qualidade que, acreditamos, este programa deve ter.

\section{NURSING SPECIALIZATION PROGRAM - A MODEL OF RESIDENCE: EXPERIENCE OF SETTING UP IT IN A SCHOOL-HOSPITAL}

This is a report about the experience of setting up a Specialization Program for Nurses in a "Residence" format, at the school-hospital of the Federal University of São Paulo, which mixes the traditional structure of specialization programs in Brazil with the model of the resident physician practical training. It began on february 1995, with the following objectives: 1) to qualify 
nurses, in different specialities, by an intensive training program, on a full-time schedule; 2) to contribute to improve the process of nursing care and; 3) to increase the quality of nursing assistance in our hospital.. The results of our experience allow us to suggest that's a good way to qualify nurses for the best nursing practice, and to increase nursing research in a very practical basis.

KEY WORDS: specialization, nursing, nursing-residency

\section{CURSO DE ESPECIALIZACIÓN EN ENFERMERÍA - MODALIDAD RESIDENCIA: EXPERIENCIA DE IMPLANTACIÓN EN UN HOSPITAL-ESCUELA}

Relatamos aqui la implantación de un Curso de Especialización en Enfermería en la Modalidad "Residencia" en el Hospital Escuela de la Universidad Federal de São Paulo, cuja estructura respeta las exigencias legales para los cursos de PostGrado "Latus-Sensus", sin embargo con características semejantes a las de la Residencia Médica, en lo que se dice respecto al desenvolvimiento de las actividades prácticas. Este curso fue iniciado en Febrero de 1995, con los siguientes objetivos: 1) capacitar enfermeras, en diversas arreas de especialidad, a través de un intenso programa de entrenamiento en servicio, en régimen de tiempo integral y dedicación exclusiva; 2) contribuir con la implementación del cuidado sistematizado de enfermería; y 3) mejorar la calidad de la asistencia de enfermería dada en el Hospital São Paulo. Los resultados nos llevan a creer que este sea un camino para preparar Enfermeras que presten una asistencia con calidad, además de colaborar para el desarrollo de trabajos científicos orientados hacia la práctica profesional.

TÉRMINOS CLAVES: especialización, enfermería, enfermería-residencia

\section{REFERÊNCIAS BIBLIOGRÁFICAS}

\section{ASSOCIAÇÃO BRASILEIRA DE ENFERMAGEM.}

Recomendações do Seminário sobre a Residência em Enfermagem. Rev.Bras.Enfermagem, Brasília, v. 32, p. 121-125, 1979.

02. ASSOCIAÇÃO BRASILEIRA DE ENFERMAGEM.

Documento da Oficina sobre "Diretrizes para a Residência em Enfermagem no Brasil". Salvador, 17 a 19 de agosto de 1994.

03. BRASIL. Câmara dos Deputados. Projeto de Lei $\mathbf{n}^{0}$ 2.264/1996. Institui a Residência em Enfermagem e dá outras providências. Relator: Deputado Paulo Rocha (PT-PA). (Documento digitado).

04. BRASIL. Conselho Federal de Educação. Resolução $n^{\circ} 12 / 83,6$ out. 1983. Fixa condições de validade dos certificados de cursos de aperfeiçoamento e especialização para o Magistério Superior, no sistema federal. Relator: Lafayette de Azevedo Pondé. Documenta, Brasília, n. 275, p. 149-150, nov. 1983.

05. BRASIL. Conselho Federal de Enfermagem.

Documento final sobre Residência de Enfermagem. Rio de Janeiro, 1994.

06. BRASIL. Conselho Federal de Enfermagem. Anteprojeto de Lei. Dispõe sobre a Residência em Enfermagem, e a sua respectiva Comissão Nacional. Rio de Janeiro, 1996.
07. BRASIL. Conselho Federal de Enfermagem. Considerações sobre o Projeto de Lei $n^{\circ}$ 2.264/ 1996. Institui a Residência em Enfermagem e dá outras providências. Relator: Doranilde Barbosa. Informe Parlamentar, Brasília, $n^{\circ}$ 5/97, 10 mar. 1997.

08. BRASIL. Conselho Nacional de Saúde. Parecer sobre o Projeto de Lei $n^{0}$ 2264/1996. Relator: Lucimar Coser Cannon. Brasília, 06 mar.1997. Aprovado na $63^{\mathrm{a}}$ reunião ordinária do CNS.

09. BRASIL. Lei no 6.932 de 07 de julho de 1981. Dispõe sobre as atividades do médico residente e dá outras providências. Diário Oficial da União, Brasília, 09 de julho de 1981. Seção 1.

10. DONABEDIAN, A. The definition of quality and approaches to its assessment. Ann Harbor: Health Administration Press, 1980. v. 1.163 p.

11. LIMA, D.M.; PORTO, M.E.A. Residência em Enfermagem - subsídios para possíveis estudos. Enf.Novas Dimensões, v. 3, n. 5, p. 294-298, 1977.

12. MICHEL, J.L.M.; VIEIRA, C.M.; GUTIERREZ, M.G.R. .Especialistas em Enfermagem MédicoCirúrgica: há interesse neste profissional? Acta Paul. Enfermagem, São Paulo, n. 1-4, p. 26-35, jan/dez. 1992. 